IZA DP No. 5395

Selective Immigration Policies, Migrants' Education and Welfare at Origin

Simone Bertoli

Herbert Brücker

December 2010 


\title{
Selective Immigration Policies, Migrants' Education and Welfare at Origin
}

\author{
Simone Bertoli \\ RSCAS, EUI \\ Herbert Brücker \\ University of Bamberg, \\ $I A B$ and IZA
}

\section{Discussion Paper No. 5395 \\ December 2010}

\author{
IZA \\ P.O. Box 7240 \\ 53072 Bonn \\ Germany \\ Phone: +49-228-3894-0 \\ Fax: +49-228-3894-180 \\ E-mail: iza@iza.org
}

Any opinions expressed here are those of the author(s) and not those of IZA. Research published in this series may include views on policy, but the institute itself takes no institutional policy positions.

The Institute for the Study of Labor (IZA) in Bonn is a local and virtual international research center and a place of communication between science, politics and business. IZA is an independent nonprofit organization supported by Deutsche Post Foundation. The center is associated with the University of Bonn and offers a stimulating research environment through its international network, workshops and conferences, data service, project support, research visits and doctoral program. IZA engages in (i) original and internationally competitive research in all fields of labor economics, (ii) development of policy concepts, and (iii) dissemination of research results and concepts to the interested public.

IZA Discussion Papers often represent preliminary work and are circulated to encourage discussion. Citation of such a paper should account for its provisional character. A revised version may be available directly from the author. 
IZA Discussion Paper No. 5395

December 2010

\section{ABSTRACT \\ Selective Immigration Policies, Migrants' Education and Welfare at Origin}

Destination countries are progressively shifting towards selective immigration policies. These can effectively increase migrants' average education even if one allows for endogenous schooling decisions and education policies at origin. Still, more selective immigration policies reduce social welfare at origin.

JEL Classification: F22, J24, H52, 015

Keywords: international migration, selective immigration policies, education policies, social welfare

Corresponding author:

Simone Bertoli

Robert Schuman Centre for Advanced Studies

European University Institute

Via delle Fontanelle 19

I-50014, San Domenico di Fiesole

Italy

E-mail: sb3151@gmail.com

\footnotetext{
* The authors gratefully acknowledge financial support from the TEMPO project funded by NORFACE and from the TOM project funded by the 6th framework programme of the EU. The authors wish to thank Sascha Becker, Tito Boeri, Giovanni Facchini, Anna Maria Mayda and Giovanni Peri for their useful comments; the authors are also grateful to the participants to the fRDB XI European Conference, Pisa, May 2009, where an earlier draft of this paper was presented; the usual disclaimers apply.
} 


\section{Introduction}

This paper analyzes the impact of skill-selective immigration policies on migrants' education and welfare in the sending countries in a model where schooling decisions and education policies at origin are endogenously determined. More and more destination countries are moving towards the adoption of immigration policies which out-select applicants on the basis of human capital criteria. ${ }^{1}$ The effects of this policy shift depends upon how would-be migrants adjust their schooling choices, and upon the possible changes in public policies towards education at origin.

Our analysis draws on the literature on the beneficial brain drain (Mountford, 1997; Stark, Helmenstein, and Prskawetz, 1997; Beine, Docquier, and Rapoport, 2001), which is built upon the idea that would-be migrants' schooling choices are endogenous with respect to the prospect to migrate. In his seminal contribution to this literature, Mountford (1997) argues that selectivity can improve the private incentives to invest in education, as would-be migrants want "to be [better] eligible for emigration". This represents only a part of the story, as policy makers in origin countries do not behave as passive bystanders in the contest for talent, but rather adjust their education policies in response to changes in immigration policies. Such a reaction is induced by the fact that the policy stance at destination affects the social return to education as well as the private incentives to bear a larger share in the costs of education.

The model that we propose is related to other papers that analyze the effects of a greater labor mobility on the financing of education (Justman and Thisse, 1997) and on migrants' average education (Stark and Wang, 2002; Docquier, Faye, and Pestieau, 2008). In contrast to the theoretical models by Stark and Wang (2002) and Docquier, Faye, and Pestieau (2008), which assume that destination countries adopt general immigration policies that do not out-select applicants by their skill-level, our model considers not only the effects of a greater openness but also the effects of a greater selectivity, which is becoming an increasingly salient feature of immigration policies.

Our theoretical analysis reveals that a shift towards a more selective immigration policy which keeps the scale of migration unchanged improves the average level of schooling of the immigrants, and of the stayers at origin. While such a policy shift is beneficial for the

\footnotetext{
1 "Countries that are non-selective and have relatively few highly skilled immigrants [...] may be most likely to demand increased levels of highly skilled migration in the future" (OECD, 2009).
} 
countries of destination, it is detrimental for the sending countries, where social welfare falls notwithstanding the adjustment of education policies following the change in the migration prospects.

\section{Selective immigration policies and schooling choices}

We consider a small open economy populated by one-period lived agents. We assume perfect credit markets, and no heterogeneity across agents as in Stark and Wang (2002) and Docquier, Faye, and Pestieau (2008). An agent endowed with $s$ years of schooling earns a $\log$ wage $\omega_{0}(s)$ which is given by

$$
\omega_{0}(s)=\mu_{0}+\delta_{0} s
$$

We assume that education gives rise to positive intra-generational externalities, so that the baseline component $\mu_{0}$ in (1) is an increasing function of the average level of schooling in country $0, s_{0}$. For the sake of simplicity, we assume a linear relationship between $\mu_{0}$ that and $s_{0}$

$$
\mu_{0}=\xi_{0} s_{0}
$$

The private cost of acquiring schooling, $c(s)$, is increasing and convex in $s$

$$
c(s)=\gamma_{0}\left(1-\sigma_{0}\right) s^{2},
$$

where $\gamma_{0}$ is a cost-shifter parameter and $\sigma_{0}$ is a public education subsidy (Mayr and Peri, 2009). The subsidy $\sigma_{0}$ is financed with a lump-sum tax $\tau_{0}$, whose amount is determined by the equilibrium condition of the fiscal balance ${ }^{2}$

$$
\tau_{0}=\sigma_{0} c\left(s_{0}^{e}\right)
$$

\footnotetext{
${ }^{2}$ We assume risk neutrality, as it is standard in the literature, so that it is immaterial to specify whether the government levies taxes only on non-migrants, or it also imposes a Bhagwati-tax on migrants (Bhagwati, 1979).
} 
where $s_{0}^{e}$ is the equilibrium level of schooling. Agents can opt for migration to a foreign country, ${ }^{3}$ where log wages $\omega_{1}(s)$ follow

$$
\omega_{1}(s)=\mu_{1}+\delta_{1} s .
$$

We assume that $\mu_{1}>\mu_{0}$, while we do not introduce any assumption on the domestic and foreign private returns to schooling $\delta_{0}$ and $\delta_{1} \cdot{ }^{4}$ Migration is a probabilistic event whose outcome is unknown when agents make their schooling choices, and an agent with $s$ years of schooling who applies for migration has a probability $p(s) \geq 0$ to be admitted at destination. We assume that $p(s)$ is non-decreasing in $s$, so that we allow destination countries to confer a better chance to migrate to better educated applicants.

Given $p(s)$, which we assume to be differentiable in $s$, a risk-neutral agent choses $s$ so to maximize expected utility

$$
E U(s)=[1-p(s)] \omega_{0}(s)+p(s) \omega_{1}(s)-c(s)-\tau_{0} .
$$

Given (1)-(5), the first order condition for the maximization of (6) is represented by ${ }^{5}$

$$
\delta_{0}+p(s)\left(\delta_{1}-\delta_{0}\right)+p^{\prime}(s)\left[\omega_{1}(s)-\omega_{0}(s)\right]=2 \gamma_{0}\left(1-\sigma_{0}\right) s .
$$

The private return to schooling on the left hand side of (7) is a weighted average of $\delta_{0}$ and $\delta_{1}$, plus a positive term that depends the differential in log wages between the two countries, and on the extent to which the education-migration probability profile $p(s)$ rewards an

\footnotetext{
${ }^{3}$ See Bertoli (2010) for a migration model where foreign wages are only locally observable, i.e. they cannot be observed before migration occurs.

${ }^{4}$ The empirical literature has not yet reached a consensus on the relationship between the level of income of a country and the private returns to schooling: the extensive review by Psacharopoulos and Patrinos (2004) suggests that "the returns are lower in the high-income countries of the OECD", while Banerjee and Duflo (2005) argue that "the returns to one more year of education are [...] no higher in poor countries", and Barro and Lee (2010) recently provided evidence that the private rate of return to an additional year of schooling is higher in advanced countries than in lower-income countries. Furthermore, the literature suggests that relative migration costs decline with schooling (Chiquiar and Hanson, 2005; McKenzie and Rapoport, 2010), and it is the foreign return to schooling net of migration costs which drives schooling decisions at origin (Bertoli and Brücker, 2010).

${ }^{5}$ Throughout the paper, we assume that (7) suffices to uniquely identify the optimal schooling choice, i.e. (6) is concave in $s$.
} 
additional year of schooling in terms of better chances to migrate. For analytical convenience, we assume that $p(s)$ is an affine function of schooling $s$

$$
p(s)=\varphi+\kappa s,
$$

with due restrictions on $\varphi$ and $\kappa$ which ensure that $0 \leq p(s) \leq 1 .^{6}$ Under the functional specification in (8), we can explicitly define the utility-maximizing level of schooling $s_{0}^{a}$

$$
s_{0}^{a}=\frac{\delta_{0}+\varphi\left(\delta_{1}-\delta_{0}\right)+\kappa\left(\mu_{1}-\mu_{0}\right)}{2\left[\gamma_{0}\left(1-\sigma_{0}\right)-\kappa\left(\delta_{1}-\delta_{0}\right)\right]} .
$$

The choice of $s_{0}^{a}$ depends - via $s_{0}^{a}$ - on the schooling choices of the other agents, which in equilibrium need to be identical; combining (9) and (2), we can derive the equilibrium level of schooling $s_{0}^{e}$

$$
s_{0}^{e}=\frac{\delta_{0}+\varphi\left(\delta_{1}-\delta_{0}\right)+\kappa \mu_{1}}{2\left[\gamma_{0}\left(1-\sigma_{0}\right)-\kappa\left(\delta_{1}-\delta_{0}-\frac{\xi_{0}}{2}\right)\right]} .
$$

\subsection{The optimal education subsidy $\sigma_{0}^{*}$}

The optimal level of the education subsidy $\sigma_{0}$ is determined by the maximization of the social welfare function; we assume here that the government wish to maximize the expected utility of the representative domestic agent. ${ }^{7}$ Such a choice entails that the social return to schooling that drives the choice of $\sigma_{0}$ does not respond to domestic factors alone, as it would do if the social welfare function was defined only on non-migrants' utilities. Hence, the objective of the social planner is to maximize social welfare $W$, which is given by

$$
W\left(s_{0}^{e}\right)=E U\left(s_{0}^{e}\right),
$$

subject to the equilibrium condition for the fiscal balance in (4). The first order condition for the constrained maximization problem faced by the social planner is given by

\footnotetext{
${ }^{6}$ Observe that (8) can be thought as a linear approximation of a more general education-migration probability profile $p(s)$.

${ }^{7}$ Stark and Wang (2002) assume that the government maximizes the utility of the non-migrants, but they suggest that different implications could be derived "if the problem of the social planner in the presence of the possibility of migration is perceived as maximizing the ex ante expected net earnings", and here we analyze the implications of this alternative assumption.
} 


$$
\frac{\partial W\left(s_{0}^{e}\right)}{\partial \sigma_{0}}=\frac{\partial s_{0}^{e}}{\partial \sigma_{0}}\left[\left[1-p\left(s_{0}^{e}\right)\right]\left(\xi_{0}+\delta_{0}\right)+p\left(s_{0}^{e}\right) \delta_{1}+\kappa\left[\omega_{1}\left(s_{0}^{e}\right)-\omega_{0}\left(s_{0}^{e}\right)\right]-2 \gamma_{0} s_{0}^{e}\right]=0
$$

With some tedious but straightforward algebra it is easy to verify that the optimal education subsidy $\sigma_{0}^{*}$ which satisfies $(12)$ is

$$
\sigma_{0}^{*}=\frac{\kappa}{2 \gamma_{0}} \xi_{0}+\frac{\xi_{0}(1-\varphi)}{\delta_{0}+\xi_{0}+\varphi\left(\delta_{1}-\delta_{0}-\xi_{0}\right)+\kappa \mu_{1}}\left[1-\frac{\kappa}{\gamma_{0}}\left(\delta_{1}-\delta_{0}-\xi_{0}\right)\right],
$$

and the adoption of $\sigma_{0}^{*}$ induces the socially optimal level of education $s_{0}^{*}$

$$
s_{0}^{*}=\frac{\xi_{0}+\delta_{0}+\varphi\left(\delta_{1}-\xi_{0}-\delta_{0}\right)+\kappa \mu_{1}}{2\left[\gamma_{0}-\kappa\left(\delta_{1}-\xi_{0}-\delta_{0}\right)\right]} .
$$

When there are no options to migrate, i.e. $\varphi=\kappa=0$, then the optimal level of the subsidy is $\frac{\xi_{0}}{\delta_{0}+\xi_{0}}$, and the resulting optimal level of schooling is $\frac{\xi_{0}+\delta_{0}}{2 \gamma_{0}}$.

\subsection{Changes in immigration policies and migrants' skills}

Changes in the shape of $p(s)$ influence both the private incentives of the agents in country 0 to invest in education, and the education subsidy which is set by the government. From (14), we can observe that the combined impact of this two distinct effects is given by

$$
\frac{\partial s_{0}^{*}}{\partial \varphi}=\frac{\left(\delta_{1}-\xi_{0}-\delta_{0}\right)}{2\left[\gamma_{0}-\kappa\left(\delta_{1}-\xi_{0}-\delta_{0}\right)\right]}
$$

and by

$$
\frac{\partial s_{0}^{*}}{\partial \kappa}=\frac{\omega_{1}\left(s_{0}^{*}\right)-\omega_{0}\left(s_{0}^{*}\right)}{2\left[\gamma_{0}-\kappa\left(\delta_{1}-\xi_{0}-\delta_{0}\right)\right]}>0 .
$$

In words, a marginal increase in the baseline probability to migrate $\varphi$ produces an impact on $s_{0}^{*}$ which is ambiguous, ${ }^{8}$ while a greater selectivity increases the average skill level of the migrants as well as that of the population at the country of origin.

We can implicitly define a family of functions $f_{s}(\varphi)$, such that an immigration policy $p(s)$ characterized by $\left(\varphi, f_{s}(\varphi)\right)$ determines an average education of the migrants equal to

\footnotetext{
${ }^{8}$ The ambiguity would not be resolved by introducing assumptions on the private returns to schooling in the two countries; (15) is positive (negative) if the private return to schooling at destination is higher (lower) than the social return to schooling at origin, with this asymmetry following from the fact that the government does not internalize the impact of its education policies on the country of destination.
} 
Figure 1: Increasing migrants' skill levels for a given scale of migration

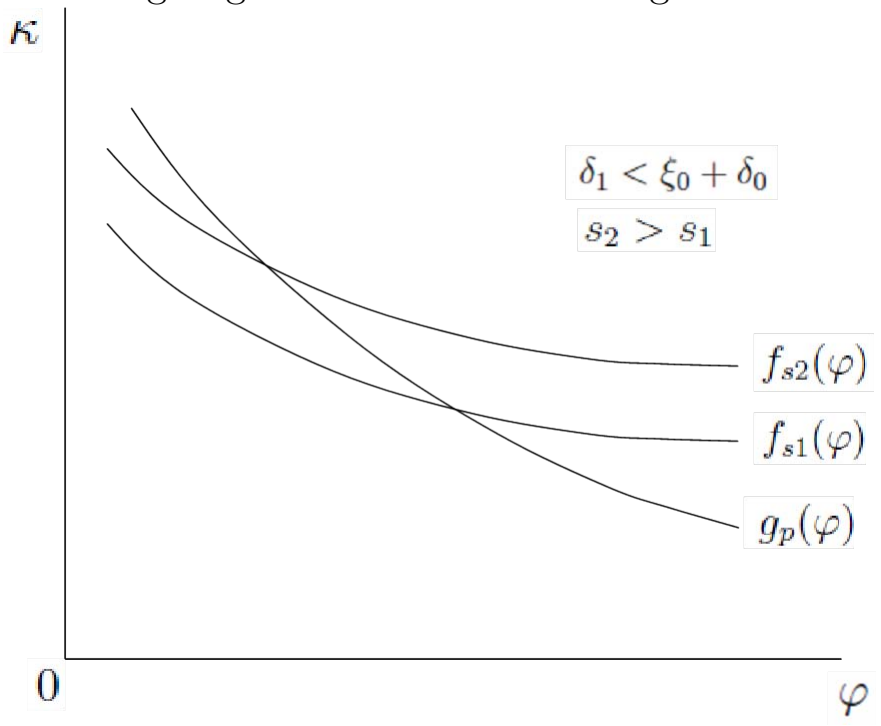

s. Combining (15) and (16), we can observe that

$$
f_{s}^{\prime}(\varphi)=\frac{\delta_{1}-\xi_{0}-\delta_{0}}{\omega_{1}\left(s_{0}^{*}\right)-\omega_{0}\left(s_{0}^{*}\right)},
$$

whose sign coincides with the sign of $(15)$. The family of functions $f_{s}(\varphi)$ identifies a map of curves in the $(\varphi, \kappa)$ space, where higher curves correspond to a higher migrants' skills.

\subsection{Changes in immigration policies and the scale of migration}

A marginal variation in the pair $(\varphi, \kappa)$ which identifies the function $p(s)$ also influences the scale of migration, which is proportional to $p\left(s_{0}^{*}\right)$; we can implicitly define a family of functions $g_{p}(\varphi)$, such that an immigration policy $p(s)$ characterized by $\left(\varphi, g_{p}(\varphi)\right)$ gives rise to a scale of migration which is proportional to $p\left(s_{0}^{*}\right)=p$. The implicit function theorem implies that

$$
g_{p}^{\prime}(\varphi)=-\frac{1+\kappa \frac{\partial s_{0}^{*}}{\partial \varphi}}{s_{0}^{*}+\kappa \frac{\partial s_{0}^{*}}{\partial \kappa}}<0 .
$$

It is easy to prove that, for any pair $(\varphi, \kappa)$, the following relationship holds

$$
g_{p}^{\prime}(\varphi)<f_{s}^{\prime}(\varphi)
$$


This entails that a marginal reduction in $\varphi$ along the graph of the function $g_{p}(\varphi)$ improves migrants' skills while leaving the scale of migration unchanged, as depicted in Figure 1. Differently from Docquier, Faye, and Pestieau (2008), Figure 1 also evidences that destination countries can become more open to immigration while simultaneously increasing immigrants' average level of schooling: this occurs whenever we move from a point $(\varphi, \kappa)$ towards a point that lies above both the $g_{p}(\varphi)$ and $f_{s}(\varphi)$ schedules. $^{9}$

\subsection{Selectivity and welfare at origin}

Which is the impact upon the social welfare in the country of origin when the country of destination increases the selectivity of its migration policy to improve migrants' education levels? More specifically, what happens with a marginal reduction in $\varphi$ along the graph of the function $g_{p}(\varphi)$, so that the policy shift towards selectivity occurs with an invariant scale of migration? We can apply the envelope theorem to the social welfare function $W$ together with (12) to observe that

$$
\left[\frac{\partial W\left(s_{0}^{*}\right)}{\partial \varphi}+g_{p}^{\prime}(\varphi) \frac{\partial W\left(s_{0}^{*}\right)}{\partial \kappa}\right] \partial \varphi=\left[\omega_{1}\left(s_{0}^{*}\right)-\omega_{0}\left(s_{0}^{*}\right)\right] \partial \varphi .
$$

There are conflicting interests in the setting of immigration policies, as (20) reveals that a shift towards a greater selectivity at destination, i.e. a lower $\varphi$, reduces the social welfare in the country of origin of the migrants, notwithstanding the adjustment of the education subsidy in the face of a changing immigration policy.

\section{Concluding remarks}

This paper demonstrates that selective immigration policies can be an effective tool for increasing migrants' education when considering endogenous individual schooling choices and optimal education subsidies at origin. Though a greater selectivity increases the average level of schooling of the stayers, it unambiguously reduces social welfare in migrants' sending countries. The predicted divergence suggests that the influence exerted by the prospect to

\footnotetext{
${ }^{9}$ Docquier, Faye, and Pestieau (2008) argue that origin countries react to a higher probability of migration for their workers by cutting down education subsidies to such an extent that migrants' average level of education actually declines, so that "the beneficial brain drain hypothesis hardly resists a normative analysis".
} 
migrate upon stayers' average education, which represents the focus of the beneficial brain drain literature, might not be informative about its impact on welfare at origin.

\section{References}

Banerjee, A. V., And E. Duflo (2005): "Growth Theory Through the Lens of Development Economics," in Handbook of Economic Growth, ed. by P. Aghion, and S. N. Durlauf. Elsevier, Volume 1A.

Barro, R. J., And J.-W. Lee (2010): "A New Data Set of Educational Attainment in the World, 1950-2010," mimeo, Harvard University.

Beine, M., F. Docquier, and H. Rapoport (2001): "Brain drain and economic growth: theory and evidence," Journal of Development Economics, 64, 275-289.

Bertoli, S. (2010): "The informational structure of migration decision and migrants' selfselection," Economics Letters, 108(1), 89-92.

Bertoli, S., AND H. BrüCKer (2010): "Extending the case for a beneficial brain drain," Jahrbücher frür Nationalökonomie und Statistik, forthcoming.

Bhagwati, J. (1979): "International migration of the highly skilled: economics, ethics and taxes," Third World Quarterly, 1, 17-30.

Chiquiar, D., and G. H. Hanson (2005): "International Migration, Self-Selection, and the Distribution of Wages: Evidence from Mexico and the United States," Journal of Political Economy, 113(2), 239-281.

Docquier, F., O. Faye, and P. Pestieau (2008): "Is migration a good substitute for education subsidies?," Journal of Development Economics, 86, 263-276.

Justman, M., And J.-F. Thisse (1997): "Implications of the mobility of skilled labor force for local public funding of higher education," Economics Letters, 55, 409-412.

Mayr, K., And G. Peri (2009): "Brain Drain and Brain Return: Theory and Application to Eastern-Western Europe," The B.E. Journal of Economic Analysis and Policy, 9(1), Article 49 (Contributions). 
McKenzie, D. J., and H. Rapoport (2010): "Self-selection patterns in Mexico-U.S. migration: The role of migration networks," The Review of Economics and Statistics, $92(4), 811-821$.

MountFord, A. (1997): "Can a brain drain be good for growth in the source economy?," Journal of Development Economics, 53(2), 287-303.

OECD (2009): The Future of International Migration to OECD countries. Paris: OECD.

Psacharopoulos, G., and H. A. Patrinos (2004): "Returns to investment in education: a further update," Education Economics, 12(2), 111-134.

Stark, O., C. Helmenstein, and A. Prskawetz (1997): "A brain gain with a brain drain," Economics Letters, 86, 227-234.

Stark, O., and Y. WANG (2002): "Inducing human capital formation: migration as a substitute for subsidies," Journal of Public Economics, 86(1), 29-46. 